\title{
KLASIFIKASI OSTEOARTHRITIS BERBASIS DUAL TREE COMPLEX WAVELET TRANSFORM DAN CONTRAST LIMITED ADAPTIVE HISTOGRAM EQUALIZATION (CLAHE) MENGGUNAKAN ACTIVE SHAPE MODELS
}

\author{
Mohammad Meizaki Fatihin ${ }^{1}$, Farid Baskoro ${ }^{2}$, Arif Widodo ${ }^{3}$ \\ 1,2,3 Jurusan Teknik Elektro, Fakultas Teknik, Universitas Negeri Surabaya \\ ${ }^{1}$ mohammadfatihin16050874040@mhs.unesa.ac.id \\ ${ }^{2}$ faridbaskoro@unesa.ac.id \\ 3arifwidodo@unesa.ac.id
}

\begin{abstract}
Abstrak
Citra adalah representasi dari informasi yang terkandung di dalamnya sehingga mata manusia dapat menganalisis dan menafsirkan informasi sesuai dengan tujuan yang diharapkan. Salah satu bentuk citra medis adalah citra $x$-ray. Penelitian ini mengidentifikasi gambar $x$-ray Osteoarthritis Lutut yang diambil pada berbagai tingkat keparahan, mulai dari KL-Grade 0 hingga KL-Grade 4. Penelitian ini menggunakan metode CLAHE dan DTCWT untuk proses preprosessing dan menggunakan metode Active Shape Model (ASM) untuk proses segmentasi, menggunakan 35 data pelatihan dan 200 data uji dari Osteoarthritis Initiative (OAI). Pengujian citra uji dalam penelitian ini dengan mengekstraksi tekstur citra menggunakan metode GLCM dan segmentasi citra menggunakan ASM, sehingga proses scanning untuk penentuan titik-titik yang berfungsi untuk mengukur ketebalan cartilage. Hasil Ekstraksi tekstur memiliki tingkat akurasi klasifikasi KL-Grade 0 57,5\%, KL-Grade 1 memiliki akurasi 33.3\%, KL-Grade 2 37,5\%, KL-Grade 3 37,5\% dan KL-Grade 4 34,3\%. Sedangkan untuk pengukuran ketebalan tulang rawan memiliki akurasi klasifikasi untuk KL-Grade 0 sebesar $62.5 \%$, kemudian KL-Grade 1 sebesar 44.4 $\%$, sedangkan untuk KL-Grade 2 memiliki keberhasilan klasifikasi 60\%, kemudian KL-Grade 3 memiliki klasifikasi berhasil dengan benar 70\%, dan untuk KL-Grade $451.4 \%$.
\end{abstract}

Kata Kunci : DTCWT, CLAHE, ASM, image processing, matlab, Osteeoarthritis

\begin{abstract}
Image is a representation of the information contained therein so that the human eye can analyze and interpret the information in accordance with the expected goals. One form of medical image is $\mathrm{x}$-ray image. This study identifies $\mathrm{x}$-ray images of knee osteoarthritis taken at various severity levels, ranging from KL-Grade 0 to KL-Grade 4. This study uses the CLAHE and DTCWT methods for the preparation process and uses the Active Shape Model (ASM) method for segmentation processes , using 35 training data and 200 test data from the Osteoarthritis Initiative (OAI). Testing the test image in this research by extracting the texture of the image using the GLCM method and image segmentation using ASM, so that the scanning process for the determination of points that serves to measure the thickness of the cartilage. Results Texture extraction has a classification accuracy level of KL-Grade 0 of $57.5 \%$, KL-Grade 1 has an accuracy of $33.3 \%$, KL-Grade 2 of $37.5 \%$, KL-Grade 3 of $37.5 \%$ and KL-Grade 4 of $34.3 \%$. As for the measurement of cartilage thickness it has an classification accuracy for KL-Grade 0 of $62.5 \%$, then KL-Grade 1 of $44.4 \%$, while for KL-Grade 2 has a classification success of $60 \%$, then KL-Grade 3 has a successful classification correctly of $70 \%$, and for KL-Grade $451.4 \%$.

Keywords: DTCWT, CLAHE, ASM, image processing, matlab, Osteeoarthritis
\end{abstract}

\section{PENDAHULUAN}

Citra adalah representasi dari informasi yang didalamnya dapat dianalisa dan diolah untuk tujuan yang diharapkan [1]
Pencitraan medis adalah proses menciptakan visual representasi dari struktur internal organ dalam tubuh yang ditutupi oleh kulit dan tulang. Pencitraan medis adalah bagian dari pencitraan biologis. Salah satunya bentuk dari citra medis 
adalah citra $x$-ray [2]. Data citra yang digunakan dalam penelitian ini adalah 303 citra $x$-ray, yang terdiri dari 25 citra untuk proses pelatihan dan 258 data uji [3]. Sebelum proses pengujian, citra Lutut dapat dinormalisasi menjadi $2828 \times 2320$ sebelum proses preprosessing. Citra input terdiri dari tulang Lutut kanan dan tulag Lutut kiri [4].

Metode CLAHE menetapkan nilai maksimum untuk klip histogram dan redistribusi piksel yang terpotong sama rata untuk masing-masing tingkat abu-abu yang dapat membatasi noise sambil meningkatkan gambar kontras [5]. Resolusi dapat ditingkatkan dengan menggunakan interpolasi diarahkan tepi berbasis kovarian bersama dengan DTCWT. Komponen gambar yang berbeda bergabung bersama untuk membentuk gambar resolusi tinggi. Karena metode ini melibatkan proses bertingkat, jumlah perhitungan lebih banyak sehingga waktu simulasi meningkat [6].

Dalam penelitian ini akan diidentifikasi adalah citra x-ray Osteoarthritis Lutut yang diambil dari berbagai tingkat keparahan dari penderita KL-Grade 0 sampai KL-Grade 4. Perbedaan setiap kategori dapat dibedakan berdasarkan tekstur tulang lutut penderita Osteoarthritis dan tingkat ketebalan cartilage pada sendi lutut karena adanya kerusakan struktur dan fungsi kartilago artikular.

Perumusan masalah pada penelitian ini adalah implementasi algoritma Active Shape Models berbasis Dual Tree Complex Wavelet Transform dan Contrast Limited Adaptive Histogram Equalization (CLAHE) untuk klasifikasi penyakit. Osteoarthritis dan mengukur tingkat akurasi klasifikasi Osteoarthritis berbasis Dual Tree Complex Wavelet Transform dan Contrast Limited Adaptive Histogram Equalization (CLAHE) Menggunakan Active Shape Model. .

Tujuan dari penelitian ini adalah mengimplementasikan pengolahan citra digital untuk penyakit Osteoarthritis dengan menggunakan Matlab R2018a dan mengukur tingkat akurasi metode berbasis Dual Tree Complex Wavelet Transform Dan Contrast Limited Adaptive Histogram Equalization (CLAHE) menggunakan Active Shape Model dalam klasifikasi penyakit Osteoarthritis.

Urgensi penelitian tentang klasifikasi Osteoarthritis Lutut adalah karena tingginya penderita Osteoarthritis. Dalam pendeteksian Osteoarthritis Dokter Ortopedi menggunakan citra $x$-ray secara manual, maka mendiagnosa tingkat penyakit Osteoarthritis pada Lutut agar dapat diklasifikasi berdasarkan algoritma yang diterapkan dalam pengolahan citra medis dengan input citra $x$-ray sangat diperlukan.

Pengolahan citra $x$-ray untuk proses preprosessing menggunakan metode DTCWT dan CLAHE untuk perbaikan citra sehingga bisa untuk menganalisa tekstur tulang dan menggunakan metode Active Shape Models untuk segmentasi citra. Penentuan titik dengan pelabelan ROI untuk menentukan nilai minimum dan luas cartilage sebagai indicator mengukur ketebalan cartilage tulang Lutut.

\section{TINJAUAN PUSTAKA \\ Osteoarthritis}

Osteoartritis (OA), kondisi muskuloskeletal yang paling umum, adalah penyakit kronis jangka panjang yang melibatkan kerusakan tulang cartilage pada sendi yang m enyebabkan tulang Tibia dan tulang Femur bergesekan, menciptakan kekakuan dan gangguan pergerakan [7].

Sistem penilaian dalam OA digunakan penilaian Kellgren-Lawrence (KL). Sistem penilaian KL menggunakan 4 tingkatan yakni KL- Grade 0, KL- Grade 1, KL- Grade 2, KLGrade 3, dan KL- Grade 04.Setiap Level dari KL-Grade ditunjukan pada gambar 1 sebagai berikut.

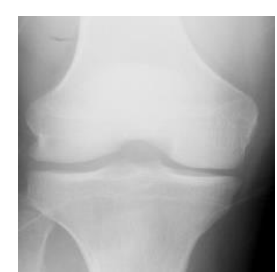

(a)

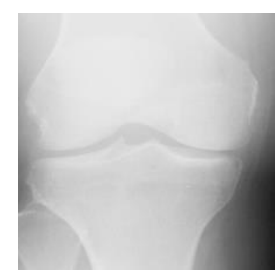

(c)

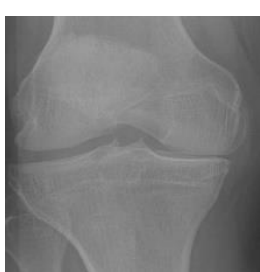

(b)

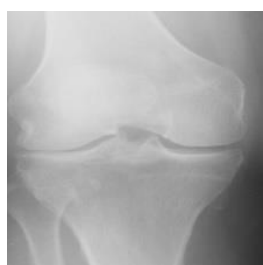

(d) 


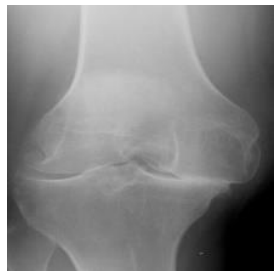

(e)

Gambar 1. Citra $x$-ray Lutut (a) KL-Grade 0 (b) KL-Grade 1 (c) KL-Grade 2 (d) KL-Grade 3 (e) KLGrade 4

\section{CLAHE}

CLAHE metode yang populer untuk peningkatan kontras lokal yang berguna untuk beberapa aplikasi. CLAHE telah banyak digunakan untuk meningkatkan kontras citra di beberapa aplikasi komputer dan aplikasi pengenalan pola. Di bidang medis, berhasil diterapkan dalam peningkatan citra mamografi, segmentasi gambar sel, pemrosesan citra pembuluh retina, dan dalam peningkatan citra fraktur tulang $[8]$.

Proses perbaikan citra dengan menggunakan CLAHE, ditentukan oleh nilai Number of Tile yang berfungsi untuk membagi citra menjadi sub-bagian citra dan penentuan nilai Clip limit yang berfungsi untuk membatasi nilai Histogram.

\section{DTCWT}

Complex Wavelet Transform (CWT) adalah salah satu transformasi wavelet terbaru yang digunakan dalam pemrosesan citra. CWT citra satu tingkat menghasilkan dua citra subband frekuensi rendah bernilai kompleks dan enam citra subband frekuensi tinggi bernilai kompleks citra input dibagi menjadi beberapa subband kecil yang menunjukkan respons magnitudo puncak di hadapan fitur citra yang berorientasi pada $+75^{\circ},+45^{\circ},+15^{\circ},-15^{\circ},-45^{\circ}$, dan $-75^{\circ}$.

DT-CWT digunakan untuk menguraikan input citra beresolusi rendah ke dalam subband yang berbeda. Kemudian, citra subband frekuensi tinggi dan citra input diintegrasikan, diikuti dengan menggabungkan semua citra ini untuk menghasilkan citra resolusi tinggi baru dengan menggunakan invers DT-CWT [9]

\section{Active Shape Model (ASM)}

ASM merupakan teknik pemodelan shape deformable yang terdiri dari 3 tahapan, yaitu (1). Tahap shape mode. Objek akan direpresentasikan menggunakan sejumlah titik-titik yang dapat mewakili objek tersebut. Pelabelan titik-titik tersebut dilakukan secara manual pada sejumlah kontur objek yang akan membentuk shape model. (2). Pada tahap model training ASM dibagi atas 2 stage. (a). Pemodelan profil masing-masing landmark yang menggambarkan wilayah karakteristik citra yang dibentuk dari proses training. (b). Shape model mendifinisikan posisi relatif yang diijinkan dari landmark. (3) Hasil dari shape model yang telah mengalami penyesuaian bentuk akan dicari sebuah model statistik yang akan dijadikan sebagai template citra yang selanjutnya ialah proses segmentasi citra [10].

\section{Gray Level Co-occurrence Matrix (GLCM)}

Matrix yang memiliki jumlah pasangan pixel dengan kecerahan tertentu yang setiap pasangan pixel terpisah dengan jarak d dan memiliki sudut inklasi $\theta$ dengan arah pixel tetangga diagonal, horizontal, dan vertical [11]. Ekstraksi tekstur dengan metode GLCM sebagai berikut [12]:

1. Contrast (Kontras)

Merupakan ukuran penyebaran (momen inersia) dari elemen matrik citra. Nilai kontras akan besar jika jauh dari diagonal utama. Nilai kontras suatu citra dapat dicari dengan persamaan 1 sebagai berikut:

$$
\sum_{i, j=1}^{N} P(i, j)(i-j)^{2}
$$

Dimana :

$\mathrm{P}(\mathrm{i}, \mathrm{j})=$ distribusi probabilitas pada baris $\mathrm{i}$ dan kolom $\mathrm{j}$

\section{Correlation (korelasi)}

Nilai correlation menunjukan ketergantungan linear derajat keabuan suatu citra sehingga menghasilkan adanya struktur linear suatu citra.. Nilai correlation dapat ditentukan dengan persamaan 2 sebagai berikut.

$$
\sum_{i, j=1}^{N} \frac{\left(i-\mu_{i}\right)\left(j-\mu_{j}\right) P(i, j)}{\sigma_{i} \sigma_{j}}
$$


Dimana :

$\mu \_\mathrm{i}=$ rata- rata berdasarkan sampel $\mathrm{i}$

$\mu_{\perp} \mathrm{j}=$ rata- rata berdasarkan sampel $\mathrm{j}$

$\sigma_{-} \mathrm{i}=$ Variasi berdasarkan sampel i

$\sigma_{-} \mathrm{j}=$ Variasi berdasarkan sampel $\mathrm{j}$

\section{Energy (energi)}

Energy merupakan distribusi intensitas piksel terhadap jangkauan aras keabuan. Nilai energy suatu citra dapat ditentukan dengan persamaan 3 sebagai berikut.

$$
\sum_{i, j=0} P(i, j)^{2}
$$

4. Homegeneity (homogenitas)

Mengukur tingkat homogenitas perulangan struktur tekstur. Nilai homegeneity suatu citra dapat ditentukan dengan persamaan 4 sebagai berikut.

$$
\sum_{i, j=1}^{N} \frac{P(i, j)}{1+|i-j|}
$$

\section{Region of Interest (ROI)}

Mendefinisikan ROI dengan membuat mask biner. Dalam mask pada citra, piksel yang menentukan wilayah ROI diatur dalam indeks bernilai 1 dan semua piksel lainnya diatur dalam indeks bernilai 0 [13].

\section{METODOLOGI PENELITIAN}

Pendekatan penelitian ini menggunakan metode kuantitatif, karena data dalam penelitian ini disajikan berupa angka dan menggunakan statistik [14].

\section{Perancangan Aplikasi}

Dalam membuat aplikasi klasifikasi OA melalui beberapa tahapan. Tahapan dalam proses klasifikasi Osteoarthritis dimulai dari proses pengambilan citra sampai penyimpanan output dalam database. Diagram alir dalam membuat software klasifikasi Osteoarthritis dengan menggunakan Matlab R2018a ditunjukkan gambar 2.

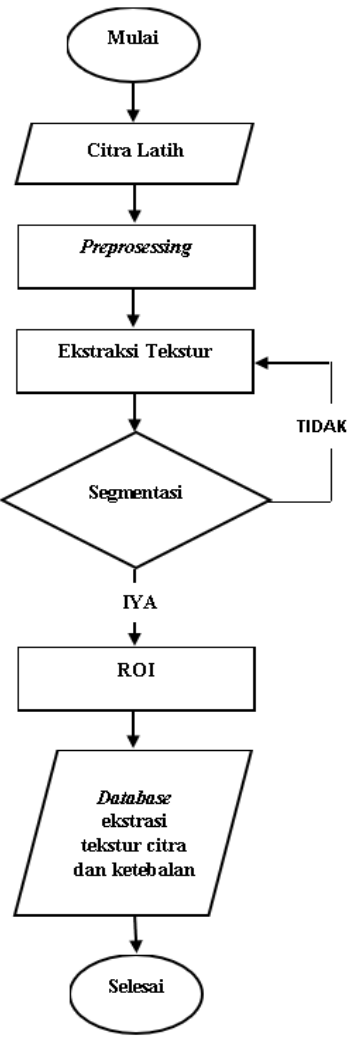

Gambar 2. Diagram sistem database

Penjelasan diagram alir pembuatan sistem database:

1. Memanggil Citra Latih

Digunakan untuk memanggil citra yang tersimpan pada direktori disk dengan ekstensi “.jpg” dan Data citra yang digunakan bersumber dari Osteoarthritis Initiative (OAI). Kemudian dilakukan proses normalisasi agar citra memiliki dimensi yang sama.

2. Preprossessing

Merupakan proses perbaikan citra dengan menggunakan metode CLAHE dan DTCWT untuk pengurangan noise pada citra.

\section{Ektraksi tekstur}

Ekstraksi tekstur dengan metode GLCM berdasarkan parameter contrast, correlation, energy dan homogeneity

4. Segmentasi

Segmentasi citra menggunakan metode ASM untuk segmentasi tulang Femur dan tulang Tibia pada citra x-ray Lutut. Tujuan dari segmentasi adalah mendukung 
pengukuran luas dan nilai minimum antara tulang Tibia dan tulang Femur agar diketahui ketebalan dari cartilage.

5. ROI

Penentuan wilayah ROI pada tulang Tibia dan tulang Femur dilakukan dengan proses scanning. Perhitungan jarak antara wilayah region of interest tulang Tibia dan tulang Femur dengan menggunakan rumus Euclidean distance.

6. Database ekstrasi tekstur citra dan ketebalan cartilage

Database adalah kumpulan dari beberapa file yang tersimpan. Database menyimpan nilai dari ekstrasi tekstur dan ketebalan cartilage.

\section{Desain Sistem}

Pembuatan desain sistem menggunakan Matlab 2018a dengan menggunakan fitur GUI. Desain GUI ditunjukan pada gambar 3 sebagai berikut.

Tampilan GUI terdiri dari:

1) 5 axis yang terdiri dari 1 axis untuk menampilkan citra input yang sudah melalui proses normalisasi, 1 axis untuk menampilkan hasil dari proses preprosessing dengan menggunakan metode CLAHE dan DTCWT dan 3 axis digunakan untuk proses segmentasi dengan metode ASM.

2) 3 tabel yang akan menampilakan hasil dari ekstraksi tekstur dengan metode GLCM, menampilkan hasil dari perhitungan jarak antara tulang Tibia dan tulang Femur / ketebalan cartilage yang akan dicari nilai minimum dari 3 titik tersebut dan tabel untuk menampilkan luas dari ketebalan cartilage

3) 7 tombol yang terdiri dari tombol setup untuk proses pengambilan citra dan proses normalisasi citra, tombol proses untuk melakukan proses preprosessing dengan DTCWT dan CLAHE, 2 tombol untuk proses ASM, tombol JAC untuk proses scanning dan perhitungan ketebalan cartilage, tombol close untuk keluar dari tampilan GUI dan tombol reset berfungsi untuk menghapus data yang sudah ditampilkan dalam GUI.

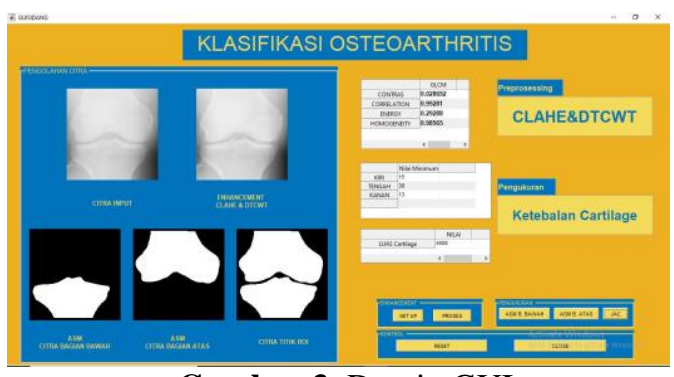

Gambar 3. Desain GUI

\section{HASIL DAN PEMBAHASAN}

\section{Data Penelitian}

Data citra terdiri dari citra latih dan citra uji. Citra latih merupakan citra yang digunakan untuk data pelatihan dan citra uji digunakan untuk proses pengujian sistem. Citra latih berjumlah 35 citra yang terdiri dari 7 citra disetiap KL-Grade dan citra uji sebanyak 200 citra. Citra bersumber dari Osteoarthritis Initiative [15].

\section{Preprosessing}

Sebelum melakukan proses preprosessing, terlebih dahulu dilakukan normalisasi citra menjadi ukuran 512x512. Kemudian merubah citra RGB menjadi HSI untuk meningkatkan nilai intensitas (I) citra sebesar 1.4. Citra hasil peningkatan intensitas diubah menjadi citra RGB kembali kemudian diubah menjadi citra abu-abu. Proses preprosessing menggunakan CLAHE dengan nilai Clip Limit 0.001 dan dengan nilai Number of Tile berukuran [4 4]. Selanjutnya menggunakan filter Local Adaptive DTCWT

\section{Proses Ekstraksi Tekstur}

Citra hasil preprosessing kemudian melalui ekstraksi tekstur menggunakan GLCM. Hasil ekstraksi tekstur data latih KL-Grade 0, KL-Grade 1, KL-Grade 2, KL-Grade 3, dan KLGrade 4 ditunjukan gambar 4 - gambar 8 sebagai berikut.

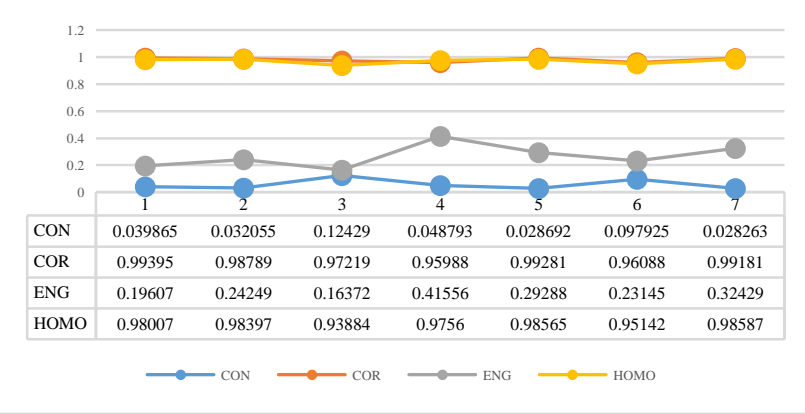

Gambar 4. Hasil Contrast, Correlation, Energy, dan Homogeneity data pelatihan KL-Grade 0 


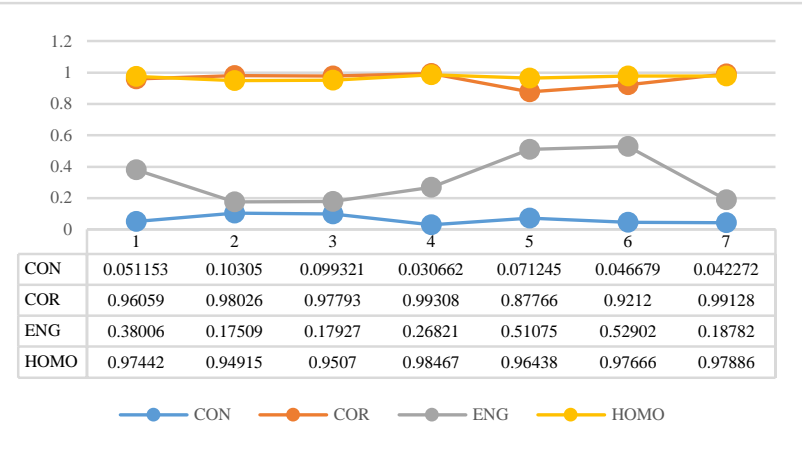

Gambar 5. Hasil Contrast, Correlation, Energy, dan Homogeneity data pelatihan KL-Grade 1

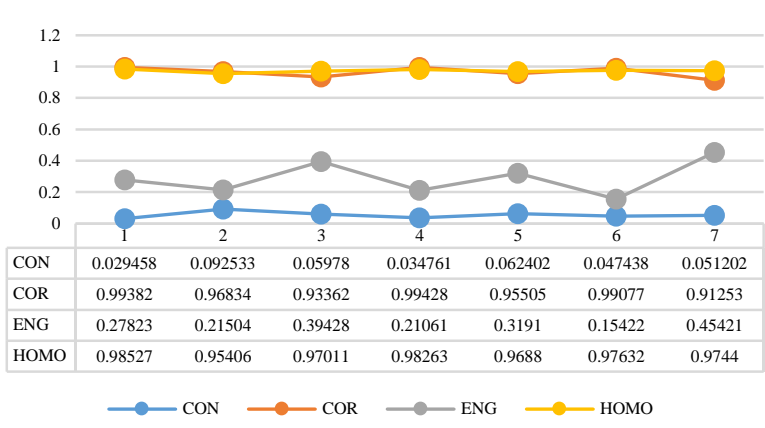

Gambar 6. Hasil Contrast, Correlation, Energy, dan Homogeneity data pelatihan KL-Grade 2

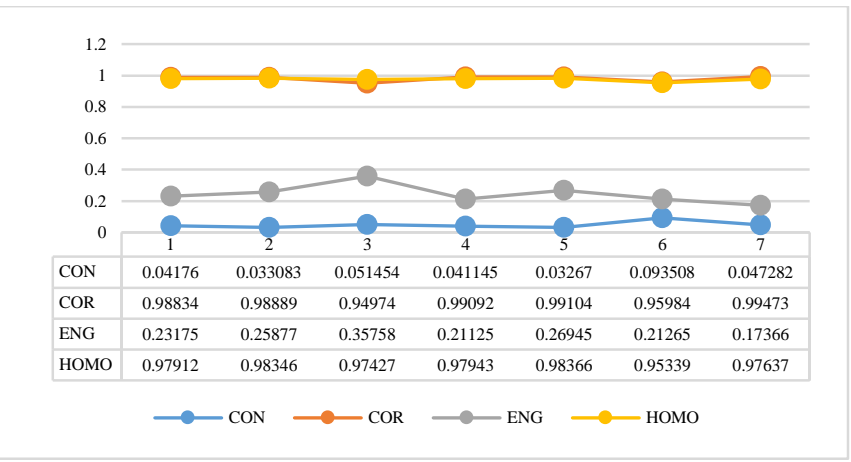

Gambar 7. Hasil Contrast, Correlation, Energy, dan Homogeneity data pelatihan KL-Grade 3

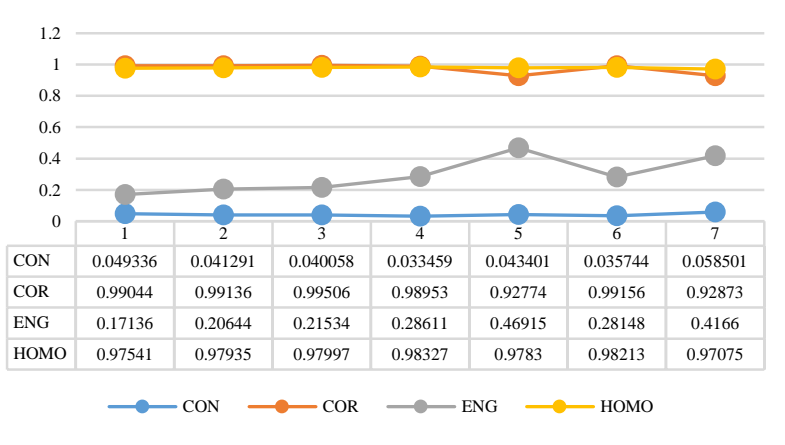

Gambar 8. Hasil Contrast, Correlation, Energy, dan Homogeneity data pelatihan KL-Grade 4
Menentukan nilai Threshold dapat mengunakan persamaan 5 sebagai berikut.

Threshold $=\frac{(\text { nilai } \max +\text { nilai } \min )}{2}$

Nilai threshold menjadi nilai tengah untuk menentukan range. Berdasarkan gambar 4 - gambar 8 , didapatkan nilai range hasil ekstraksi tekstur ditunjukan pada tabel 1 sebagai berikut.

Tabel 1 Hasil nilai range GLCM

\begin{tabular}{|c|c|}
\hline KL-Grade & Nilai Range \\
\hline KL-Grade 0 & $0.54976-05748591$ \\
\hline KL-Grade 1 & $0.550058-0.58422388$ \\
\hline KL-Grade 2 & $0.57013625-5980855$ \\
\hline KL-Grade 3 & $0.5480105-0.56563575$ \\
\hline KL-Grade 4 & $0.5466365-0.57564213$ \\
\hline
\end{tabular}

\section{Segmentasi}

Citra hasil proses preprosessing digunakan untuk metode Active Shape Models. Citra hitam putih hasil segmentasi digunakan untuk pengukuran ketebalan cartilage.

Pengukuran luas ketebalan cartilage dilakukan dengan inisialisasi posisi titik awal koordinat $(\mathrm{x}, \mathrm{y})$ pada koordinat $(100,250)$. Selanjutnya memperbanyak titik scanning kearah kanan sejauh 282 pixel sehingga titik akhir pada koordinat $(382,250)$ sehingga memiliki 282 titik scanning. Setelah titik scanning sudah ditentukan, kemudian melakukan scanning pada gambar hasil segmentasi hingga menemukan nilai index citra bernilai 1 terakhir sebelum citra bernilai index 0 dengan pelabelan menggunakan ROI. Hasil scanning 282 titik disimpan pada sebuah matrix untuk gambar hasil segmentasi atas dan hasil segmentasi bawah. Luas ketebalan cartilage dihitung dengan cara mencari selisih dari matrix segmentasi bawah dengan matrix segmentasi atas. Kemudian melakukan integral untuk mendapatkan luas ketebalan cartilage.

Nilai minimum dicari dengan menentukan 3 titik yaitu dengan mencari titik kanan, titik tengah, dan titik kiri. Inisialisasi titik tengah dengan koordinat $(\mathrm{x}, \mathrm{y})$ diletakkan pada tulang Tibia. Kemudian titik tengah tersebut akan dikurangi 
nilai $\mathrm{x} /$ kolom sebesar 141 pixel sehingga mendapatkan titik sebelah kiri dengan koordinat (x-141,y) dan menambahkan 141 pixel untuk mendapatkan titik koordinat pada sisi kanan tulang dengan koordinat $(\mathrm{x}+141, \mathrm{y})$. Proses scanning menggunakan 3 titik tersebut akan berhenti ketika sudah mencapai pixel dengan index 1 terakhir pada ketiga titik. Kemudian melakukan pelabelan menggunakan ROI dan pengukuran dengan menggunakan rumus Euclidean distance. Hasil dari ketiga titik tersebut dicari nilai minimum sehingga dapat untuk menambah akurasi pengukuran ketebalan cartilage.

Hasil dari pengukuran luas ketebalan cartilage dan nilai minimal ketebalan cartilage digunakan untuk mengukur ketebalan cartilage tulang Lutut.

Hasil pengukuran ketebalan cartilage pada tulang Lutut dengan menggunakan data pelatihan KL-Grade 0, KL-Grade 1, KL-Grade 2, KL-Grade 3, dan KL-Grade 4 ditunjukan oleh gambar 9 - gambar 13 sebagai berikut.

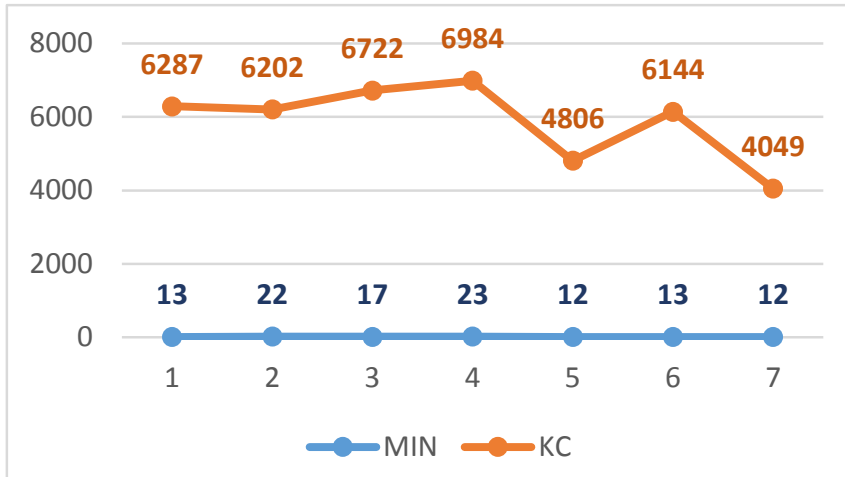

Gambar 9. Luas ketebalan cartilage dan nilai minimal ketebalan cartilage data pelatihan KL-Grade 0

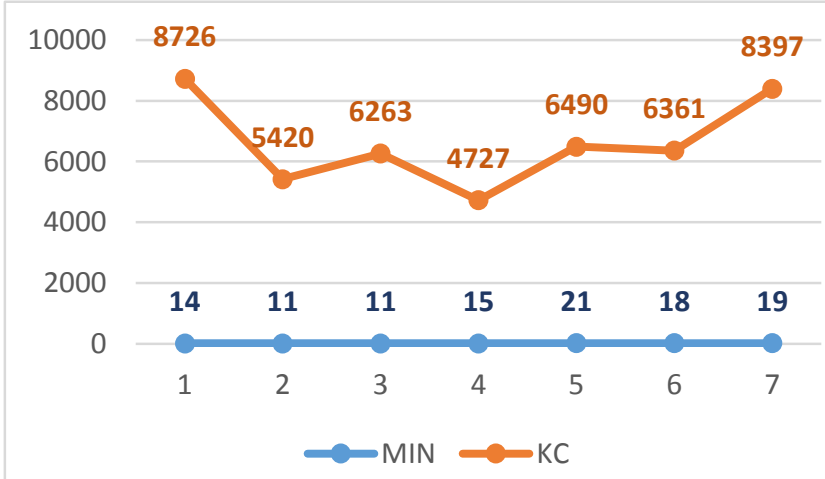

Gambar 10. Luas ketebalan cartilage dan nilai minimal ketebalan cartilage data pelatihan KL-Grade 1

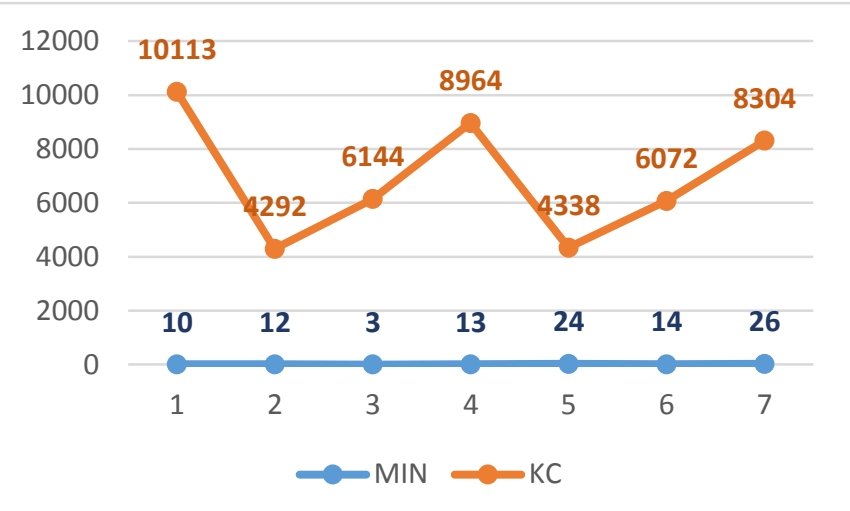

Gambar 11. Luas ketebalan cartilage dan nilai minimal ketebalan cartilage data pelatihan KL-Grade 2

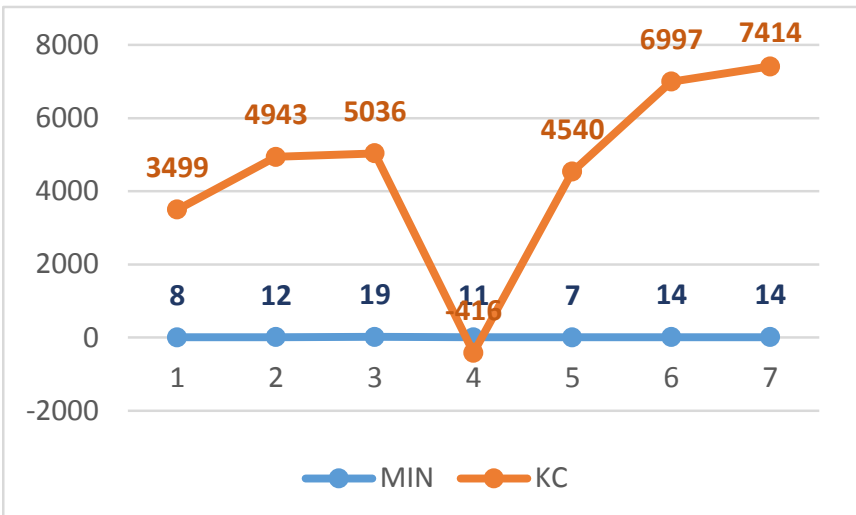

Gambar 12. Luas ketebalan cartilage dan nilai minimal ketebalan cartilage data pelatihan KL-Grade 3

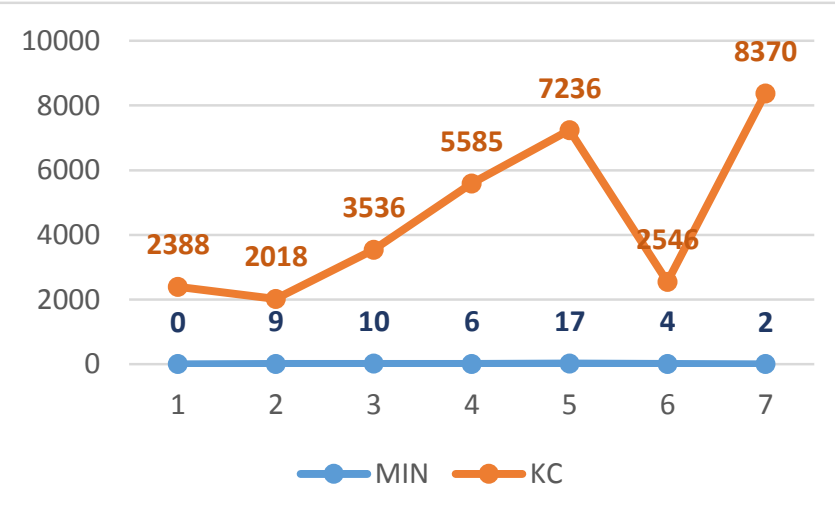

Gambar 13. Luas ketebalan cartilage dan nilai minimal ketebalan cartilage data pelatihan KL-Grade 4

Berdasarkan data citra latih luas ketebalan cartilage dan nilai minimal ketebalan cartilage pada gambar 9 - gambar 13 , maka dapat menentukan nilai range dengan menggunakan persamaan 5. Hasil nilai range terdapat pada tabel 2 dan tabel 3 sebagai berikut. 
Tabel 2 Hasil nilai Threshold Ketebalan cartilage

\begin{tabular}{|c|c|}
\hline KL-Grade & Nilai range \\
\hline KL-Grade 0 & $21.667-32.667$ \\
\hline KL-Grade 1 & $27.833-34$ \\
\hline KL-Grade 2 & $22.667-30.667$ \\
\hline KL-Grade 3 & $12.667-21$ \\
\hline KL-Grade 4 & $5.6667-17.833$ \\
\hline
\end{tabular}

Tabel 3 Hasil nilai minimal Ketebalan cartilage

\begin{tabular}{|c|c|}
\hline KL-Grade & Nilai range \\
\hline KL-Grade 0 & $12-17.5$ \\
\hline KL-Grade 1 & $11-16$ \\
\hline KL-Grade 2 & $3-14.5$ \\
\hline KL-Grade 3 & $7-13$ \\
\hline KL-Grade 4 & $0-8.5$ \\
\hline
\end{tabular}

\section{Pengujian Citra Uji}

\section{Ekstraksi tekstur}

Dari perhitungan Threshold citra latih untuk ekstraksi tekstur terdapat pada tabel 6 sebagai range untuk pengolahan citra uji. Hasil pengujian citra uji dengan menggunakan ekstraksi tekstur ditunjukan pada tabel 4.

Tabel 4 Hasil nilai citra uji ekstraksi tekstur

\begin{tabular}{|l|c|c|c|c|c|}
\hline & KL-0 & KL-1 & KL-2 & KL-3 & KL-4 \\
\hline KL-Grade 0 & $57.5 \%$ & $10 \%$ & $22.5 \%$ & $10 \%$ & $0 \%$ \\
\hline KL-Grade 1 & $0 \%$ & $33.3 \%$ & $55.5 \%$ & $11.1 \%$ & $0 \%$ \\
\hline KL-Grade 2 & $5 \%$ & $0 \%$ & $57.5 \%$ & $37.5 \%$ & $0 \%$ \\
\hline KL-Grade 3 & $10 \%$ & $5 \%$ & $42.5 \%$ & $37.5 \%$ & $5 \%$ \\
\hline KL-Grade 4 & $0 \%$ & $5.7 \%$ & $51.4 \%$ & $8.6 \%$ & $34.3 \%$ \\
\hline
\end{tabular}

Tabel 4 merupakan hasil dari klasifikasi Ostioarthritis dengan sisi horizontal merupakan hasil dari pengujian ekstraksi tekstur dengan metode GLCM. tingkat akurasi pengujian untuk KL-Grade 0 sebesar $57.5 \%$, akan tetapi kesalahan klasifikasi pada KL-Grade 1 10\%, KL-Grade $22.5 \%$, KL-Grade $310 \%$ dan tidak terjadi kesalahan pada KL-Grade 4.

Sedangkan dalam klasifikasi KL-Grade 1 dengan tingkat akurasi 33\%, dengan kesalahan klasifikasi pada KL-Grade 2 $55.5 \%$, KL-Grade $311.1 \%$, dan Tidak terjadi kesalahan klasifikasi pada KL-Grade 0 dan KL-Grade 4 dengan klasifikasi $0 \%$.

KL-Grade 2 memiliki tingkat akurasi sebesar 57.5\% dan kesalahan diklasifikasi sebagai KL-Grade 0 5\%, KL-Grade 3 $37.5 \%$ dan tidak ada kesalahan klasifikasi karena bernilai $0 \%$ pada KL-Grade 1 dan KL-Grade4.

Selanjutnya ialah KL-Grade 3, memiliki tingkat akurasi klasifikasi sebesar $37.5 \%$ yang disebabkan oleh kesalahan klasifikasi pada KL-Grade 2 sebesar 42.5\%. sedangkan terdeteksi sebagai KL-Grade 0 sebesar $10 \%$ dan KL-Grade 1 dan KL-Grade 4 sebesar 5\%.Dan pada KL-Grade 4 memiliki kesesuaian klasifikasi dengan nilai 34.3\%. Terklasifikasi sebagai KL-Grade 3 sebesar 8.6\%, KL-Grade $15.7 \%$ dan kesalahan klasifikasi terbesar terdapat pada KL-Grade 2 yaitu sebesar 51.4\%. dan KL-Grade 4 0\%.

Hasil dari klasifikasi dengan menggunakan ekstraksi tekstur ditunjukan pada gambar 14.

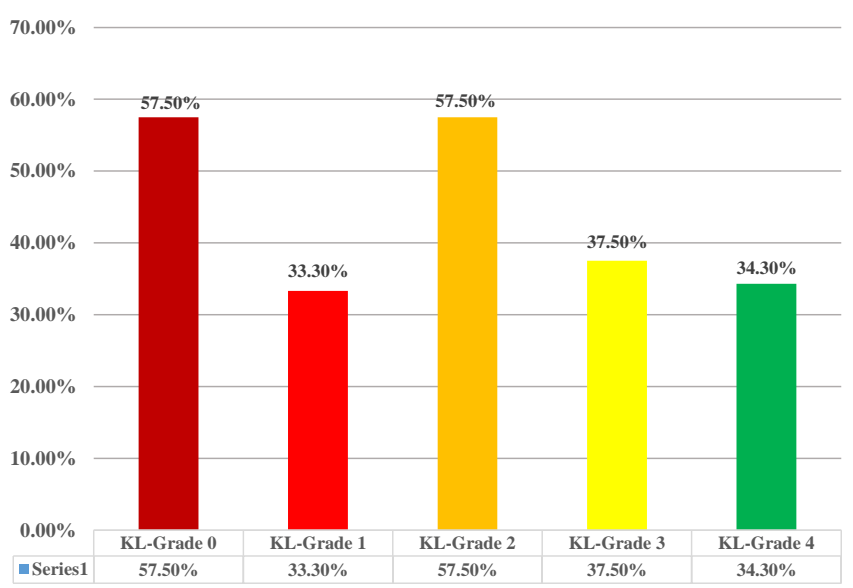

Gambar 14. Hasil ekstraksi tekstur

\section{Ketebalan cartilage}

Pengujian data uji untuk Luas ketebalan cartilage dan nilai minimal ketebalan cartilage menggunakan nilai range pada tabel 2 dan tabel 3. Hasil citra uji pengukuran ketebalan cartilage tulang Lutut ditunjukan pada tabel 5. 
Tabel 5 Hasil nilai citra uji ketebalan cartilage

\begin{tabular}{|c|c|c|c|c|c|}
\hline & KL-0 & KL-1 & KL-2 & KL-3 & KL-4 \\
\hline KL-Grade 0 & $62.5 \%$ & $20 \%$ & $12.5 \%$ & $5 \%$ & $0 \%$ \\
\hline KL-Grade1 & $40 \%$ & $44.4 \%$ & $2.2 \%$ & $8.89 \%$ & $4.44 \%$ \\
\hline KL-Grade 2 & $12.5 \%$ & $27.5 \%$ & $60 \%$ & $0 \%$ & $0 \%$ \\
\hline KL-Grade 3 & $2.5 \%$ & $10 \%$ & $10 \%$ & $70 \%$ & $7.5 \%$ \\
\hline KL-Grade 4 & $5.7 \%$ & $8.57 \%$ & $25.7 \%$ & $8.57 \%$ & $51.4 \%$ \\
\hline
\end{tabular}

Dari tabel 5, KL-Grade 0 memiliki akurasi sebesar $62.5 \%$, terklasifikasi sebagai KL-Grade $120 \%$, KL-Grade 2 $12.5 \%$, KL-Grade $35 \%$ dan KL-Grade 4 0\%. Sedangkan KLGrade 1 memiliki akurasi pengujian sebesar $44 . \%$ dan terjadi kesalahan klasifikasi sebagai KL-Grade 0 40\%, KL-Grade 2 $2.2 \%$, KL-Grade $38.89 \%$ dan KL-Grade 4 sebesar $4.44 \%$. Kemudian keberhasilan sistem dalam klasifikasi KL-Grade 2 sebesar 60\%. kesalahan klasifikasi ke KL-Grade 0 12.5\%, KLGrade 1 27.5\%, KL-Grade $30 \%$ dan KL-Grade $40 \%$. Selanjutnya KL-Grade 3 memiliki akurasi klasifikasi sebesar $70 \%$ dan terklasifikasi dalam KL-Grade 0 2.5\%, KL-1 10\%, KL-Grade 2 10\%, dan KL-Grade 4 7.5\%. Kemudian KLGrade 4 memiliki keberhasilan klasifikasi sebesar $51.4 \%$ dan kesalahan klasifikasi kedalam KL-Grade 0 5.7\%, KL-Grade 1 8.57\%, KL-Grade $225.7 \%$, dan KL-Grade $38.57 \%$.

Hasil dari klasifikasi dengan menggunakan ketebalan cartilage tulang Lutut ditunjukan pada gambar 15

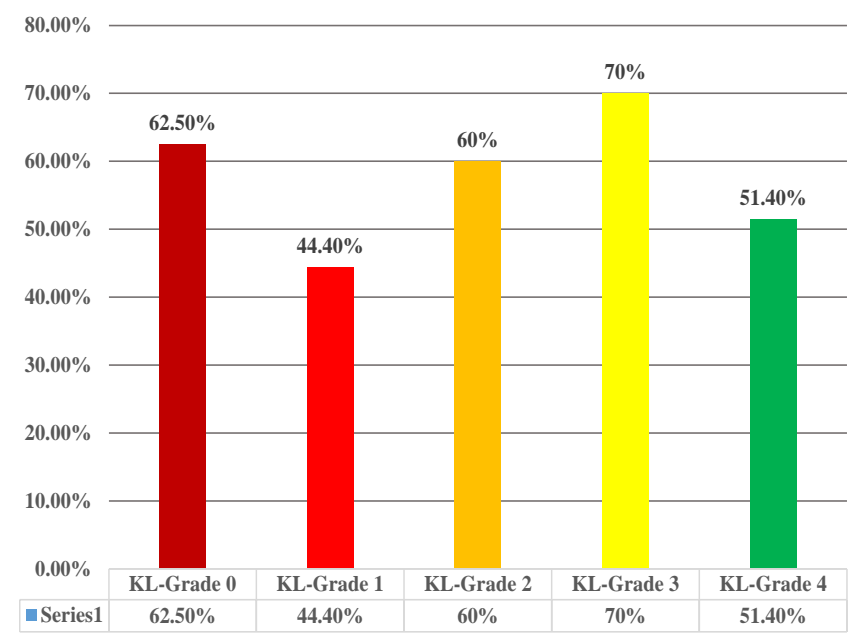

Gambar 15. Hasil ketebalan cartilage

\section{PENUTUP \\ Simpulan}

Kesimpulan penelitian ini adalah

Klasifikasi Osteoarthritis dengan menggunakan preprosessing dengan metode CLAHE dan DTCWT dan segmentasi menggunakan metode ASM dapat diimplementasikan dengan baik dengan menggunakan Matlab 2018a dengan mencari nilai dari tekstur tulang dan ketebalan cartilage tulang Lutut. Tingkat akurasi klasifikasi pada ekstraksi tekstur adalah KL-Grade 0 sebesar 57.5\%, sedangkan KL-Grade 1 memiliki akurasi sebesar 33.3\%, KL-Grade 2 sebesar 37.5\%, kemudian KL-Grade 3 sebesar 37.5\% dan KLGrade 4 sebesar 34.3\%. Kesalahan klasifikasi karena kontras kualitas citra input yang berbeda-beda. Kemudian untuk ketebalan cartilage memiliki akurasi klasifikasi untuk KLGrade 0 sebesar $62.5 \%$, KL-Grade 1 sebesar $44.4 \%$. sedangkan untuk KL-Grade 2 memiliki keberhasilan klasifikasi sebesar $60 \%$, kemudian KL-Grade 3 memiliki keberhasilan klasifikasi dengan benar sebesar 70\%, dan untuk KL-Grade 4 sebesar $51.4 \%$. Kesalahan dalam klasifikasi ketebalan cartilage karena kualitas citra hasil preprosessing masih terdapat noise sehingga mempersulit ketika roses pencarian pola pada saat segmentasi menggunakan ASM, sulitnya dalam segmentasi pada KLGrade 3 dan KL-Grade 4 karena tulang Tibia dan tulang Femur menempel atau rusak, dan KL- Grade 0 dan KL-Grade 1 yang memiliki ketebalan cartilage yang hampir sama.

\section{Saran}

Untuk penelitian selanjutnya agar menambahkan untuk metode perbaikan citra dalam proses preprosessing karena semakin baik proses hasil dari preprosessing maka penentuan wilayah saat segmentasi citra menggunakan ASM semakin mudah. Analisa tekstur dengan menggunakan metode GLCM kurang berhasil jika digunakan untuk analisa tekstur Osteoarthritis karena menghasilkan nilai output yang homogen sehingga sulit untuk dianalisa. Menggunakan perangkat keras laptop dengan processor dengan kecepatan yang tinggi agar tidak memakan waktu yang lama ketika proses segmentasi menggunakan ASM, karena perlu memproses pola citra data pelatihan terlebih dahulu.. 


\section{DAFTAR PUSTAKA}

[1] Madenda, Sarifuddin.2015. Pengolahan Citra \& Video Digital. Jakarta: Penerbit Erlangga

[2] Gornale,Shivana S. dkk. 2016. Detection of Osteoartritis using Knee X-RAY Image Analysis: A Machine Vision Based Approach, International Journal Of Computer Science And Technology. India. Rani Channamma University., DR. Babasaheb Ambedkar Maratwada University

[3] Anifah, Lilik,. dkk, 2017. Osteoarthritis Classification Using Self Organizing Map Based Gray Level Run Length Matrices. 2017 5th International Conference on Instrumentation,Communications, Information Technology, and Biomedical Engineering (ICICIBME). Indonesia. Bandung

[4] Anifah, Lilik,. dkk, 2011. Automatic Segmentation of Impaired Joint Space Area for Osteoarthritis Knee on $X$-ray Image using Gabor Filter Based Morphology Process. IPTEK, The Journal for Technology and Science, Vol. 22, No. 3

[5] Zhiyuan, Xu dkk. 2009. Fog Removal from Color Images using Contrast Limited Adaptive Histogram Equalization, IEEE 2009 2nd International Congress on Image and Signal Processing. China. Tianjin

[6] Patil, Mayuri Ddkk. 2013. Dual Tree Complex Wavelet Transform (DTCWT) based Adaptive Interpolation Technique for Enhancement of Image Resolution, International Journal of Computer Applications (0975 - 8887). Vol.08. Bhopal. TIT

[7] Wittenauer, Rachel dkk. 2013. Background Paper 6.12 Osteoarthritis, Priority Medicines for Europe and the World "A Public Health Approach to Innovation". World. Europe

[8] Campos, Gabriel. Fillipe Centini,. dkk. 2019. Machine learning hyperparameter selection for Contrast Limited Adaptive Histogram Equalization, EURASIP Journal on Image and Video Processing. Brazil. Londrina State University

[9] Demirel, Hasan,. Anbarjafari, Gholamreza. 2010. Satellite Image Resolution Enhancement Using Complex Wavelet Transform, IEEE Geoscience And Remote Sensing Letters

[10] Pangestuti, Kardiva Indah., Purnama, I Ketut Eddy. 2015. Pengukuran Sudut Tibia Dan Femur Pada Citra XRay Menggunakan Active Shape Model (ASM), Prosiding Seminar Nasional Pendidikan Teknik Informatika. Surabaya. Institut Teknologi Sepuluh Nopember

[11] Purwandani, Sri. 2019. "Identifikasi Kematangan Buah Tomat Berbasis L*a*b Color dan Gray Level Cooccurrence Matrix Menggunakan K-means Clustering”. Jurnal Teknik Elektro.Vol.08: hal. 17-20

[12] Anifah, lilik,. dkk. 2019. Prediction Of Osteoarthritis Using Linier Vector Quantization Based Texture Feature. Journal of Theoretical and Applied Information Technology, Vol. 97, No. 7
[13] MATHWORKS.1994-2020. ROI - BASED PROCESSING, (ONLINE),(HTTPS://WWW.MATHWORKS.COM/HELP/IMAGE S/ROI-BASED-PROCESSING.HTML, DIAKSES PADA 4 FEBRUARI 2020)

[14] Suryana. 2010. METODOLOGI PENELITIAN. Bandung: Universitas Pendidikan Indonesia

[15] Ostearhtritis Initiative, "Osteoarthritis.", , www.OAI.com, 2009. 